\title{
PROCESSES OF LEARNING ENGLISH IN ACADEMIC AND SOCIAL SETTING
}

\author{
Ismail Sheikh Ahmad ${ }^{a *}$, Faizah Idrus ${ }^{\text {b }}$, Zainurin Abdul Rahman ${ }^{c}$, \\ Syamsul Fozy Osman ${ }^{d}$, Muhammad Faizal A. Ghani ${ }^{\mathrm{e}}$ \\ ${ }^{a * b c}$ International Islamic University Malaysia, \\ Selangor, Malaysia.drismail@iium.edu.my, ifaizah@iium.edu.my, zainurin@iium.edu.my \\ ${ }^{\mathrm{d} K o l e j ~ P o l y-T e c h ~ M A R A, ~}$ \\ Kuala Lumpur, Malaysia, syamsul@gapps.kptm.edu.my \\ ${ }^{\mathrm{e} U n i v e r s i t y ~ o f ~ M a l a y a ~}$ \\ Kuala Lumpur, Malaysia, mdfaizal@um.edu.my
}

\begin{abstract}
This study is an attempt to gather and investigate in depth information on Malaysian university students' use of the English language in their daily interactions. Essentially, it is a qualitative phenomenological study that utilizes the interview as a tool to gather information from undergraduates of a Malaysian public university based in the Klang valley. Nine students were enquired upon the extent to which English language is used in their daily interactions and challenges that they faced in using the language. Analysis done led to five main themes that represented the pattern of their English language usage. The themes found were indicative that the uses of English language in interactions were (1) limited to needs and situation, (2) based on location and purpose, (3) affected by low self-efficacy and language skills (4) strong affective barriers and (5) unsupportive social environment. It could be said that the findings can act as an eye opener for definitive actions to be taken to improve EL interaction amongst Malaysian undergraduates towards the fulfillment of the Malaysia Education Blueprint (MEB-HE) 2015-2025 (Higher Education) aspirations.
\end{abstract}

Keywords: English language use, Social interaction 


\section{INTRODUCTION}

As a progressive nation, aspiring to be a fully developed nation, Malaysia is concerned and committed towards the development of high quality and knowledgeable human capital. The ability to interact in the English language (EL) would be pertinent if not essential towards the achievement of the goal (MOE, 2015). It is widely accepted that the ability to master the lingua franca would be generative towards knowledge transfer and the capability of a person to effectively function in social situations (Klaassen, R. and Graaff, E., 2001; Isarji Sarudin et al., 2008; Ravinder, K. et. al., 2009 and Shafie, L. A., \& Nayan, S., 2010).

Concurrently, Higher Education Institutions (HEIs) are at the receiving end of the education system by having school leavers as their students input. With respect to the EL, the HEIs are required to face a variety to proficiency levels in the students at the entry point, leaving them with challenges ranging from remedying the students who are less able to boosting the performance of those who are already proficient. Therefore, effective methods and approaches need to be identified to ensure that the HEIs EL curriculum would be able to address the needs of the students. To do so, investigations upon the needs of the students, especially for the use of English in real life scenario, i.e. the academic and social setting, would be essential.

Malaysia's higher education system has faced many critical challenges to produce quality graduates in its quest to fulfill the needs of domestic and global labor markets. The Malaysia Education Blueprint (MEB-HE) 2015-2025 (Higher Education), launched by the Ministry of Education (MOE) in April 2015, focused on many new priorities, including the importance of balanced graduates of Malaysian universities imbued with language skills, good moral conduct, critical thinking and communication skills has set a new milestone to be achieved by higher education institutions. On the other hand, employers too raised concerns that employability skills among university graduates and English language skill are major criteria for employability especially in the private sector (Shafie and Nayan, 2010).

Information on how the undergraduates learned English before they enrolled as university students is scarce. Once they become part of the university's students, we need to examine the problems and challenges that they faced to identify what are the coping mechanisms and strategies used in acquiring the language. At present, knowledge on how the students utilize the English language in their daily social interactions within and outside the classroom environment is scanty.

Hence, it is crucial to probe into the students' English language (EL) learning processes and the language's daily usage in the quest of supporting and enhancing their language skills and consequently increase their employability skills. Thus, this study seeks to examine the phenomenon of EL usage across the four main language skills among the undergraduates and aspires to present the results of a qualitative phenomenological study on the perception of and experiences in learning English among the undergraduate students.

\section{Language proficiency stated in The Malaysian Education Blueprint 2015-2025}

The MEB-HE 2015-2025 is founded upon five major system aspirations with an emphasis on 'Quality' in that the quality of graduates is one of the three areas being focused on. It is aspired that quality graduates will eventually increase the employability rate from the current $75 \%$ to $80 \%$ by 2025 (MOE, 2015). Besides that, it is endeavored that higher education teaching and learning would develop individuals who are balanced in the sense of knowledge and skills as well as ethics and moral. In order to achieve the aspiration, six primary attributes are focused upon acting as continuity to the educational efforts in the school system. One of the attributes identified is Language Proficiency whereby Malaysian graduates are expected to be 
proficient in a minimum of two languages namely (1) Bahasa Malaysia and (2) English. The aspiration is not a surprise because the issue of English language proficiency amongst Malaysian university graduates is not new and it "seems to resonate a feeling of uneasiness with the graduates' level of English proficiency" (Isarji, 2008).

\section{Proficiency and Productivity in Academic and Social Interaction}

Local and global competitiveness is a major factor that made of EL important as a medium of interaction. Added with socio-economic demands and information technology development, English is viewed as an important global language for communication and career advancement. More often than not, related studies on EL as the major medium of instruction in the local universities focused more on the perspectives of curriculum designers (The Ministry of Education and syllabus designers in the university), implementers (lecturers) and material developers (textbooks publishers).

Students' perspectives (perceptions, learning processes and social usage) of EL in the university are found to be to be under researched. There are gaps on how EL, particularly as a medium of instruction and a vehicle for social interaction, can be best taught, used or applied from the students' perspectives. Typically, how students view and perceive the language, to some degree, may influence their learning behaviors and academic achievement (Klaassen and Graaff, 2001).

A number of critical factors affecting the students learning the language such as motivation and goal orientation may shape the perceptions and beliefs in learning the language and its functions in their daily lives (Ravinder, K., 2009). However, these factors should not be viewed as working in isolation but the factors and other related affecting factors should be observed in a contextualized manner to yield better findings and meaningful solutions in helping them to be proficient in English.

Fei, Siong, Kim and Yaacob (2012), claimed that "Malaysia has had the EL indelibly woven into its history, and the language has been a constant significant factor in shaping national policies, particularly educational policies" (p. 146). This highlights the fact that the usage of EL is essential towards the development of the country and proficiency in the language is imperative. Besides that, Badrasawi, K. J., Zubairi, A., \& Idrus, F. (2016) study found that proficiency in EL has positive impact on students' identity whilst ensuring experience for the students. Therefore, the EL is influential in shaping the undergraduate students' identity and is considered as a tool to empower undergraduates' experience.

There are several studies conducted on students' experiences in learning and using EL in academic as well as social interaction. However, there is a dearth of research specifically exploring the undergraduates' experiences in learning and utilizing EL in Academic and Social interaction. For example, a study conducted by Ching-Yi Wu (2014) on Qualitative Study of Taiwanese Students Studying Abroad: Social Interactions, Navigating US Culture, and Experiences Learning English Language. This study only covered the significant relationship between the Taiwanese students studying abroad and their social interactions, navigating US culture and experiences in learning English language. This study sought evidence of the extent to which Taiwanese college students were able to participate in social interaction and learn English better by using their English experiences in US. This study, nevertheless, did not cover the importance of experience of English language towards academic studies like the one conducted by Martirosyan, Eunjin Hwang and Wanjohi (2014).

Martirosyan, Eunjin Hwang and Wanjohi (2014) conducted a study on the Impact of English Proficiency on Academic Performance of 
International Students. This study, aimed at analyzing the impact that English proficiency has on International students' academic performance in North Central Louisiana. This was a step taken to provide insights for the administrators of the institutions who wanted to encourage and boost the international students' academic performance. The result revealed that students with high level of English proficiency are likely to have highest CGPA.

Thus, a study on students' experiences in learning and utilizing EL in academic and social interaction which may impact their proficiency level among Malaysian students is timely. This is because the results found from this study could be an agency in facilitating educators to improve their teaching strategies and students' learning for a better proficiency level. By the same token, educators can produce learning strategies and models to improve students' proficiency level by understanding the kinds of experiences they have had and challenges they faced throughout their English language learning. Without these understanding, educators as well as students need to totally rely on their own strategies in teaching and learning process.

Malaysians presently, regardless of their age, identity and race are likely to be at least a bilingual, speaking the two most important languages; Bahasa Malaysia and English. This is due to the reason that Bahasa Malaysia and English are compulsory and important subjects to pass in the Malaysian education system (Wendy Hiew, 2012). Undoubtedly, learning and utilizing EL in academic and social interaction are highly encouraged among Malaysian especially undergraduates.

Undergraduates who are studying in colleges, universities or any higher institutions are expected to be able to communicate using English as many of the higher learning institutions use English as their medium of instruction. Thus, those who are less proficient in English will be at a greater loss academically. Additionally, undergraduates' experiences in learning and utilizing English language in academic and social interaction are crucial for them to get a good job and to be successful in their profession of interest.

\section{METHODS}

This is a qualitative phenomenological study due to its depth in that "instances of phenomenon in real life settings and from the perspectives of the participants involved in the phenomenon" (Gall, Gall, \& Borg, 2007, p. 634). In this context the researchers explore the essence of the experiences by uncovering the underlying themes of meaning of shared experience of the informants (Patton, 2002).

The phenomenon studied in this research is the informants' use of English in their daily interactions within the campus. The research questions for the study are:

I. To what extent do the students use the English language in typical daily interactions when they communicate with (1) native speakers or people who are more proficient in English, (2) authorities (deans, officers), (3) official occasions (presentations, meetings), (4) social occasions (casual discussions and conversations)?

II. To what extent do the students use EL in typical daily interactions in (1) asking questions and giving explanations, (2) reading text or listening to someone who is reading a text,(3) writing letters, filling up forms and writing information?

III. What are the challenges faced by students in using English in daily social interactions?

Data collection was done using semi structured interview as it allows authentic first hand information to be collected in an in-depth and detailed manner. Informants involved in this study were selected using purposeful sampling method with a focus on information rich cases (Berg, 2004). A total of 9 informants, final year undergraduate Malaysian students, studying in a Malaysian public university based in the Klang 
valley, were identified through a screening questionnaire to ensure suitability and diversity of field of study.

Prior to the interview, the informants were given explanation to the aims and importance of the study. Then, an informed consent was requested from the informants for their agreement to participate in the study and the use of recording device during the interview. A digital recorder was used to record the interview. The interview was conducted in English with the allowance for codeswitching to Bahasa Malaysia for comprehension and clarity purposes. The interviews were then transcribed verbatim for analysis purposes.

Analysis was then done in multiple stages to allow for the production of a cogent set of themes. The first analysis conducted was a preliminary exploratory analysis (Creswell, 2012) where the informants' responses were identified and categorized according to the appropriate interview questions. This is to ensure that responses with suitable main ideas were duly identified whilst discarding those that were irrelevant.

The next level of analysis conducted involves the identification of themes from each of the individual informants to be matched to the appropriate research questions. A standardized template (AT1) was used to ensure accuracy and systemize the analysis. Here, literal coding was implemented and the process resulted with nine sets of analysis from the interview process.

The third stage of the analysis is the effort of grouping the individual themes into groups by combining the individual themes. It is refinement process as what Creswell (2012) suggested as making the data sensible especially towards answering the research questions. Here, feedback patterns were traced, segmented and labeled accordingly and thus avoiding any redundancy. The process also augmented unique individualized themes for recognition. Again a standardized template (AT2) was utilized and the effort resulted with four grouped themes. The grouping could be seen in table 1 below. Throughout the process, a superscript numbering system was used to match the themes arising with the corresponding individual themes. This ensured that all the themes could be traced back to its originating source.

Table 1. Grouping of themes

\begin{tabular}{cc}
\hline Template & Grouped theme \\
\hline AT 2.1 & $\mathrm{I} 1+\mathrm{I} 2$ \\
AT 2.2 & $\mathrm{I} 3+\mathrm{I} 4$ \\
AT 2.3 & $\mathrm{I} 5+\mathrm{I} 6 \&$ I7 \\
AT 2.4 & $\mathrm{I} 8+\mathrm{I} 9$ \\
\hline
\end{tabular}

Finally, the analysis process was culminated with the identification of the main themes of the responses. Themes grouped in stage three were combined and layered to further refine and focus the themes identified. Layering is done by categorizing the grouped themes into a broader category, such as, implications of teaching and learning of EL, impact of learning EL on the informants' academic performance or impact of social environment upon EL interactions. Creswell (2012) postulated that the layering process will add "rigor and insights" to the study and make the themes more sophisticated. The process is complemented by the use of alphanumeric superscripts between the main themes and the supporting grouped themed to ensure traceability for triangulation purposes.

The analysis process could be seen as a stringent and careful process, done so to ensure the credibility and trustworthiness of the study. It could be said as a successful endeavor as the process was able to derive themes that effectively answered the research questions.

\section{FINDINGS}

Five emerging themes were derived from the analysis process in response to the research questions allowing an in depth view upon the 
informants' thoughts over the processes of learning English in the academic and social setting. Based upon the information obtained, the main themes derived were:

\section{A. Limited to needs and situations.}

Feedback from the informants indicated that the use of English in their daily lives is limited to functional needs and the situations that they are in. This insight was gained when I4: 131 in response to the question "Are you using English in your daily social interaction? Why?" informed that,

"Bila ada keperluan rasanya. [Only when there is a need, I think]"

while I5: 146 informed that, on a ten point scale, he would rate that his daily use of English as

"Kalau bagi skala tu... dibawah lima lah.

[If I were to put it on a scale, it would be lower than five]".

Interaction in English is deemed necessary mainly for academic communication at the faculty as pointed by $19: 24$,

"Because most of my lecturers are foreigner. And English is the first language in my faculty."

and I5: 144,

"Bila ada kelas. [When there is class]".

Functionally, I3: 114 outlined that at the faculty, English is used, "During meetings... society meetings, of course classes, and formal functions."

Besides that, English is found necessary in the informants' interaction with international students. I3:118 informed that,

"If I meet with someone that I did not recognize because they are look like foreigner, an international, so I will immediately speak in English..."

while I1: 34 informed that,

"If you meet your international friends then you talk in English.".
The same idea could be observed in I2:64, I4:170 and I5:52. It is also noted that, for I6\&I7: 98, their involvements in student leadership activities made it necessary for them to interact in English. It was informed that,

"In my daily routine, I need to meet a lot of people, not only the students but also to the management... so, I need to keep improving and I need to make ensure that my English is very good because of the condition of the environment I'm currently attach to".

However, in general, the informants' feedback is indicative that EL interaction is only limited to within the campus' grounds and to a certain extent unnecessary in the community. This is most apparent in I1: 62 feedback when he mentioned,

"Aaa... right now. Because I staying outside since second year. So, I don't have time to communicate with my friends.. The right time to communicate in English right now is in this university. Because most of them are students. If you go outside, you meet a very different level of people. You cannot start speaking in English ...It's difficult for me to practice English but aaaa somehow there you must."

And I5: 78, when he informed that, “... because on my surroundings all Malay speaking at home. We are speaking in Kelantan language, Kelantan dialect. And with friends also, we are speaking with the Malay words."

The same idea was conveyed by I2: 126 , I4:154, I8:36 and I9:26.

Thus, it could be seen that for the informants of this study, EL interactions will only occur if there is a need for it and according to the situation that they are in. 


\section{B. Based on location and purpose.}

Information gained from the informants indicated that the extent of English usage for social interaction according to the location and purpose of interaction.

EL use for interaction is seen to be dependent to the location where the interaction occurs. For I3:122,

English is useful for interactions in the city of Kuala Lumpur are when he informed, "My social thing, I use English. Somehow Kuala Lumpur, they use to write some instructions some information use English, so I can understand English, so I get what they are going to say, I get the point."

while for I9:26, the area of EL interaction is limited to the university campus as he informed,

"I only utilize English in my university.

Rarely outside. Maybe sometimes only.".

I8: 37 and I9:28 conveyed the same idea through their feedback.

Besides that, it was made apparent that EL interaction is done for specific purposes in order to complete tasks that the informants were involved with. Through the interview, I5: 154, revealed that,

"Contoh... ada saya... saya ada buat freelance kan, photography, ambil gambar convo dekat International Medical Science IMS, more Chinese there, so I use my English untuk tanya kerr cakap kerr. [For example, I do freelance photography, I was engaged to take convocation pictures at the International Medical Science IMS, there are many Chinese there, so I use English to communicate].".

Another example is I2: 154 revelation that during his engagement in a school,

“...I did lessons with students in Al Amin

[name of a school], and I think, in a month
I think from morning until 3.30pm I used that English as much as I can. But, just to converse with students and other teachers.".

Similar thoughts were shared by I3: 128, I1:64 and I6\&I7: 88.

Therefore, it is clear that the extent of use of EL in the context of social interaction for the informants would depend largely on the location of the interaction and its purpose.

\section{Low self efficacy and language skills.}

The interview also revealed that the informants are facing problems in interacting using EL due to the lack of self efficacy and skills.

Low self efficacy is apparently a major issue in the informants' EL interactions. I2:72 admitted that,

"I don't know. I just don't have much confidence to talk in English."

And it was further explained I4:156 revealed that, "Ada rasa tak yakin. Bukan malu, dia tak yakin. [There is a lack of confidence. Not that I am shy, but lack of confidence]"

The same trend could be seen in the responses of $\mathrm{I} 3: 30, \mathrm{I} 2: 134$ and I5:78.

Besides that, the informants felt that they are not skillful enough in the language skills for them to efficiently interact using English. It was revealed by I9: 18 ,

"My vocab is not wide enough and..ermm

I'm not really fluent in speaking. But I think, my writing is better than my speaking.".

I4:118 felt that that his lack of skills is a barrier towards EL interaction as he informed, "Kekadang kita jumpa dengan orang yang level tinggi, kita susah nak paham dia sebab dia cakap lancar, fluent dan ... itu satu lah. [Sometimes we meet those 
who are more proficient; it is difficult to understand them because they are fluent...]"

while for I8: 40,

"Sometime the foreigner students and lecturers have their own slang in English which makes me hard to understand it."

Thus, the information gained could be said as indicative to the idea that the informants lack self efficacy and skills to interact in the language.

\section{Strong affective barriers.}

Feedback from the informants has also revealed affective barriers that are influential upon their use of English as medium of interaction.

A strong affective factor would be the fear of making mistakes in EL communication. I6\&I7: 112 revealed that,

"Like for us, we are very scared in making mistakes, when I write something in English, even me, sometimes we don't send our papers, English reader papers because of we... it sounds funny but this is the thing that if you in the primary school you went to university level when you write something and "I think this not good". So we are quite...".

The same idea was revealed by I2:128 when he mentioned,

“... I don't like to make mistake, really...

I don't want people to know that I'm not really good English, but then I'm taking TESL... yes really I have this mindset."

The discomfort is further aggravated when the ability in EL is attached as a prerequisite to academic qualification. Anxiety due to the requirements leads to a discouraging feeling to interact in the language. I6\&I7: 114 revealed that,

"There is good and bad in the minimum requirement, band and everything. But it actually this discourage people to enjoy study English. It just force people to pass the English not to feel enjoy study English.".

On the other hand, I4:110 explained that for him, “...sebab bila kita belajar English ini masa zaman matric, tertumpu untuk exam, maknanya tumpuan hanya sepenuhnya pada exam. So, mungkin dia berjaya tapi kalau implementasi dalam kehidupan sehari-hari, kurang. [Because, when we learn English for examination, we will focus on the exam, entirely on passing the exam. So, we may be successful but we will lack real life implementation.]".

A similar idea was conveyed by I1:18 and I2:96.

Teachers' teaching style is also found to be influential in motivating EL interaction in the informants. I1: 16 informed that,

"My former secondary school teacher aaa not stress on aa in public speaking... They most probably on writing and the one in academic one. Urmm but as I can say, that aaa English in primary and secondary school not aa following the true communication skill...".

While I2:18 feedback makes it more apparent as he informed that,

"In the school, my teacher... actually my teacher did not really encourage to learn English..."

before making a comparison with his tuition teacher I2:110,

“... my tuition teacher really help me to... develop my skills. I think because of I learnt with her ... but then she really motivated me to learn and somehow to... to get err excellent..." and finally informing that her present lecturer

I2:166

“... I think every day she encourages to improve our English to communicate with 
her. I think, I really, I do like her class very much, really.".

A thought from I6\&I7: 125 seem to summarize the view when it was informed that,

"Like I said, I have different kind of teachers which is I can differentiate how this teacher and this teacher taught me English is different. Some teachers is very strict on how they are doing their marking the paper and how they advise us. Some teachers are very enjoy, they are just very... it's like... how can I say... they are encourage us to speak and to advice the students in the very encourage way.".

Hence, it could be seen that there is an affective barrier within the informants with respect to EL interactions brought about by the fear of making mistakes, anxiety due to academic implications and influence of the teachers' style.

\section{E. Unsupportive social environment.}

The interview carried out had also revealed that the informants felt that the social environment is not supportive of EL interactions.

It was revealed that $19: 30$ felt that,

"People around me prefer Malay rather than English.".

Even worse, I5: 120, revealed that he is stigmatized when he interacts in English in his home environment,

"Because memang err I don't know, may be Malay's perception... [ Because, I don't know, maybe it is the Malays' perception]"

and he went further to illustrate, I5: 124, "Even dalam family pun, when I speak English, they are-ape jerr English ni...? [Even with the family member, they'll be sarcastically questioning- What's this, you are speaking English?]”.
For, I3:110, the social environment does not require the need for EL interaction at all when he revealed,

"Yah, social environment, because of course when I go back to my hometown, no one speak in English, so, why I have to suddenly speak with my grammar? They don't speak in English. So... it's not really an obstacle, but then if you have a long vacation, it will leave you from speak English.".

Similar sentiments could be derived from I1:50, I4:154 and I6\&I7: 86's responses.

To add to the EL interaction conflicting environment, the informants also revealed that there is a lack of programs that would promote EL interactions. When asked if there were programs that would promote the EL interaction culture conducted, I4:152 revealed,

Tak de. Bila kita masuk UIA ni, kita dah dianggap seolah-olah bersedia untuk bertutur dalam bahasa Inggeris ni. [None, when we join UIA, it is assumed that we are ready to interact in English]".

While for I3:164, there should be more open platforms for the students to interact and develop the EL interaction skills as he pointed,

"For me, try to make more open discussion use English language, not only inside the classroom, maybe like open forum. We invite students to speak in English. There will be one of the moderators at that night on the event, somebody that we like ... encourage them. So, you join this, you can get more to practice more your English."

Feedbacks from I1:76, I5:120 and I9: 38 were also found to be parallel to these thoughts.

The feedback from the informants revealed that their social environment is not supportive of EL 
interactions as the language is not necessary for their interactions in the society and there were insufficient supporting activities for the interaction to occur.

In a nutshell, it is found that the EL social interaction trend revealed by the informants involved in this study is not encouraging. It was revealed that social interaction in the language is limited to needs and situation instead of being a common occurring behavior. Besides that, EL social interaction seems to be happening based on location and purpose of interaction instead of something being done at anytime and anywhere. The disheartening find is mainly due to the low self efficacy and language skills in the informants instead of well matured and developed abilities, the existence of strong affective barriers instead of confidence motivating thinking and a nonconducive and unsupportive social environment instead of an openly interactive society.

\section{CONCLUSION/RECOMENDATION}

The study has highlighted a non-compelling scenario of the use of EL for social interaction in Malaysian higher education setting. The themes that surfaced indicated that English is a language used in a limited situation and only done out of necessity. Indeed, this is not reflective of the aspirations of the MEB and if actions are not taken the situation may be detrimental to the blueprint's achievements. Besides that, the informants' attitude does not bode well to the of efforts spent for the teaching of the language in schools leading to the question if the current EL curriculum is too exam orientated that it neglected the development of individual's communication and interaction abilities.

Hence, at this juncture, it is the onus of the Higher Education Institutions to react and remedy the situation. It is suggested that twofold actions are taken, (1) focused on individual enhancements to improve efficacy towards EL interactions, develop confidence and enhance motivation whilst reducing concentration on accuracy of language use and (2) enculturation of EL interactions in the campus community by encouraging EL interactions even amongst students of the same social group and across ethnics or nationalities.

\section{REFERENCES}

Abdul Hamid, H. (2008). An Evaluation of The English Language Programme at The International Islamic University, Malaysia: A Case Study At The Students' Language Enhancement Unit (Sleu). (Unpublished master thesis). International Islamic University, Kuala Lumpur, Malaysia.

Badrasawi, K. J., Zubairi, A., \& Idrus, F. (2016). Exploring the relationship between writing apprehension and writing performance: A qualitative study. International Education Studies, 9(8), 134-143.

Bazeley, P. (2009). Analysing qualitative data: More than 'identifying themes'. Malaysian Journal of Qualitative Research, 2(2), 6-22.

Berg, B. L. (2004). Qualitative research methods for the social sciences (5th ed.). Pearson Education.

Brown, H. D. (1994). Principles of language learning and teaching (3rd ed.). NJ: Prentice Hall Regents.

Carson, J. G. \& Longhini, A. (2002). Focusing on learning styles and strategies: A diary study in an immersion setting. Language Learning, 52(2), 401-438.

Chin-Yi Wu. (2014). Qualitative Study Of Taiwanese Students Studying Abroad: Social Interactions, Navigating US Culture, and Experiences Learning English Language. Unpublished doctoral dissertation. Wayne State University, Detroit, USA.

Coleman, R. \& Goldenburg, C. (2010). What does research say about effective practices for English learners? Kappa Delta Pi Record, 46(2), 60-66.

Cresswell, J.W. (2012). Educational research. USA.

Creswell, J. W. (2007). Qualitative inquiry \& research design: Choosing among five approaches (2nd ed.). Sage.

De Jesus, O, N. (2014). International undergraduate English language learners perception of language and academic acquisition through online learning: A qualitative phenomenological study. Unpublished doctoral dissertation. Liberty University, Lynchburg, USA.

Denzin, N. K., \& Lincoln, Y. S. (Eds.). (1998). Collecting and interpreting qualitative materials. Sage.

Fei, W. F., Siong, L. K., Kim, L. S, \&Yaacob, A. (2012). English use as an identity marker among Malaysian undergraduates. The Southeast Asian Journal of English Language Studies, 18(1), 145 - 155.

Gall, M. D., Gall, J. P., \& Borg, W. R. (2007). Educational research: An introduction. Pearson/Allyn \& Bacon.

Haynes, J. (2007). Getting started with English language learners: How educators can meet the challenge. ASCD. 
Hiew. Wendy (2012). English language teaching and learning issues in Malaysia: Learners' perceptions via Facebook dialogue journal. Journal of Arts, Science \&amp; Commerce, 3(1), 11 - 19.

Isarji Hj Sarudin, Ainol Madziah Zubairi, Mohamed Sahari Nordin \& Mohd Azmi Omar. (2008). The English language proficiency of Malaysian public university students. In Zuraidah Mohd Don et. al (Eds.), Enhancing the quality of higher education through research: Shaping future policy (pp. 40-65). The Ministry of Higher Education Malaysia.

Ismail Sheikh Ahmad (2017). Doing qualitative research for beginners: From theory to practice. Partridge.

K. Ravinder, R. Laura, S. Kaewkuekool, \& S. Ploisawaschai. (2009). Multiple goal orientations and foreign language anxiety. System, 37 (4), 676-688.

Kim. L, S. (2001). A qualitative study of the impact of the English language on the construction of the sociocultural identities of ESL speakers. (Unpublished doctoral dissertation). University of Houston, Texas, USA.
Klaassen, R. \& Graaff, E. (2001). Facing innovation: Preparing lecturers for English-medium instruction in a non-native context. European Journal of Engineering Education, Vol.26 (3), 281-289.

Malaysian Education Ministry (2015). Malaysia Education Blueprint 2015-2025 (Higher Education). Malaysian Education Ministry.

Martirosyan, N. M., Eunjin Hwang, Wanjohi, R. (2015). Impact of English Proficiency on Academic Performance of International Students. Journal of International Students, 5(1), $60-71$.

Morita, L. (2012). English and intercultural interaction in the internationalisation of a Japanese university. Journal of Intercultural Communication, 30, 1401-1634.

Patton, M. Q. (2002). Qualitative research and evaluation methods (3rd ed.). Sage.

Shafie, L. A., \& Nayan, S. (2010). Employability awareness among Malaysian undergraduates. International Journal of Business and Management, 5(8), 119- 123. 